\title{
Simulations and Measurement Analysis of SiC MOSFET and IGBT Gate Drive Performance in Power Modules for More Electric Aircraft Motor Drive Applications
}

\author{
Shane O'Donnell ${ }^{1,2}$, Allen Chan ${ }^{1}$, Pat Wheeler ${ }^{2}$ and Alberto Castellazzi ${ }^{2}$ \\ ${ }^{1}$ MICROCHIP TECHNOLOGY \\ Gort Road Business Park \\ Ennis, Co. Clare, Ireland \\ Tel.: +353 (0) 656840044 \\ Fax: +353(0) 656822298 \\ Shane.ODonnell@microchip.com \\ http://www.microchip.com \\ ${ }^{2}$ UNIVERSITY OF NOTTINGHAM \\ University Park \\ Nottingham NG7 2RD, UK \\ Tel.: +44 (0) 1159515151 \\ Fax: +44 (0) 1159513666 \\ http://www.nottingham.ac.uk/research/groups/power- \\ electronics-machines-and-control-group/index.aspx
}

\section{Acknowledgements}

The authors wish to acknowledge the support provided by the Microchip Intelligent Power Solutions ${ }^{\mathrm{TM}}$ team.

\section{Keywords}

«Aerospace», «IGBT», «Intelligent Power Module (IPM)», «Mission Profile», «Modelling», «MOSFET», «Power semiconductor device», «Reliability», «Silicon Carbide (SiC)», «Systems engineering», «Wide bandgap devices».

\begin{abstract}
With the increase in power electronic solutions for More Electric Aircraft, silicon-carbide MOSFETs are being considered as alternatives to silicon IGBTs in areas such as motor drive systems for primary flight and landing gear actuators. In these high-reliability applications, it's essential that all aspects of the power electronics, including the semiconductor switches, are well understood to ensure correct operation for extended periods. A study on the gate-drive signals of $1200 \mathrm{~V} \mathrm{SiC} \mathrm{MOSFETs} \mathrm{in} \mathrm{two}$ different prototype power module solutions designed for More Electric Aircraft motor drive applications is presented in this paper. Measurements are recorded for various MOSFET solutions and compared with an IGBT alternative. Furthermore, a dV/dt analysis is presented and the correlation between the gate-drive signals and the $\mathrm{dV} / \mathrm{dt}$ is shown. Simulation results are validated with test bench measurements and methods for performance improvements are outlined. The data illustrates that the higher switching speed of the $\mathrm{SiC}$ devices results in increased transients and higher $\mathrm{dV} / \mathrm{dt}$ which can impact negatively on the reliability of the system. One method of reducing these effects is by variation of the gate resistance but this may have a negative impact on power dissipation and inverter efficiency as presented in this study.
\end{abstract}

\section{Introduction}

As the More Electric Aircraft (MEA) advances, hydraulic and pneumatic actuation systems are being replaced with electrical solutions [1]. This can result in lighter systems, with reduced fuel burn and a subsequent positive impact on the environment. Electro-hydrostatic (EHA) and electro-mechanical (EMA) actuators are driven by electrical motors that can be controlled and monitored by a Power Drive Electronics (PDE) system [2]. This PDE interfaces with the flight controller and can drive the motor using closed-loop control. In modern aircraft, the use of insulated gate bipolar transistor 
(IGBT) technology is the favoured approach for power converters driving electrical motors. These devices meet the fundamental requirements for the application and as they have been widely used for many years, their characteristics are well known, and their reliability is very much established.

Wide bandgap semiconductor materials, however, such as silicon carbide (SiC), have properties which offer significant advantages over silicon ( $\mathrm{Si}$ ) such as improved power density, lower losses and operation at higher junction temperatures [3] - [9]. The characteristics of SiC may result in a trade-off, however, before final component or technology selection. For example, the faster switching capability of $\mathrm{SiC}$ can result in higher $\mathrm{dV} / \mathrm{dt}$, which may lead to an increased EMI filter or potential damage to other system elements such as the electrical motor.

This paper presents test measurements and simulation analysis of the gate-drive and $\mathrm{dV} / \mathrm{dt}$ signals in 5 $\mathrm{kVA}$ power inverters designed for motor control applications in MEA. Two of these inverters contain the same $1200 \mathrm{~V}, 40 \mathrm{~m} \Omega \mathrm{SiC}$ MOSFETs, while a third unit has $80 \mathrm{~m} \Omega \mathrm{SiC}$ MOSFETs. The fourth unit used in this study comprises of silicon (Si) IGBT switches in place of SiC MOSFETs. All modules have $20 \mathrm{~A}$ anti-parallel Schottky barrier diodes (SBDs). The modules are powered from a high voltage DC supply of $540 \mathrm{~V}$ and all are tested with an inductive-resistive load for an output current of $25 \mathrm{~A}$. This is the limit of operation of these $5 \mathrm{kVA}$ modules.

Some details and measurements from the $40 \mathrm{~m} \Omega$ SiC MOSFET Power Control Modules have been previously published [10]. This paper includes advancements of that work to include measurements on a module with the SiC MOSFETs replaced by Si IGBTs. Also, dV/dt and power dissipation measurements from two of the modules are contained in this paper and the correlation between the gate-drive and the $\mathrm{dV} / \mathrm{dt}$ performance is presented. Furthermore, using simulation and measured data, solutions to modify the gate-drive characteristics and $\mathrm{dV} / \mathrm{dt}$ are proposed and validated. These can improve the long-term reliability and performance of the module and the actuator system.

\section{Integrated Power Solutions Modules}

The following integrated power solutions modules used in this study have been designed and developed by Microchip, for similar MEA motor drive applications. The units are customised for this study and therefore differ from the commercially available solutions offered by the company.

1. Power Core Module, containing $40 \mathrm{~m} \Omega$ SiC MOSFETs with total external gate resistance of $15 \Omega$ and SiC anti-parallel diodes. This is labelled PCM-SiC-40mR.

2. Power Core Module, containing $80 \mathrm{~m} \Omega$ SiC MOSFETs with total external gate resistance of $15 \Omega$ and $\mathrm{SiC}$ anti-parallel diodes. This is labelled PCM-SiC-80mR.

3. Power Core Module, containing IGBTs with external gate resistance of $10 \Omega$ and SiC antiparallel diodes. This is labelled PCM-IGBT.

4. High-Power Electronics Module, containing $40 \mathrm{~m} \Omega \mathrm{SiC}$ MOSFETs with external gate resistance of $10 \Omega$ and $\mathrm{SiC}$ anti-parallel diodes. This is labelled HPEM-SiC-40mR.

These modules are displayed in Fig. 1 and Fig. 2.

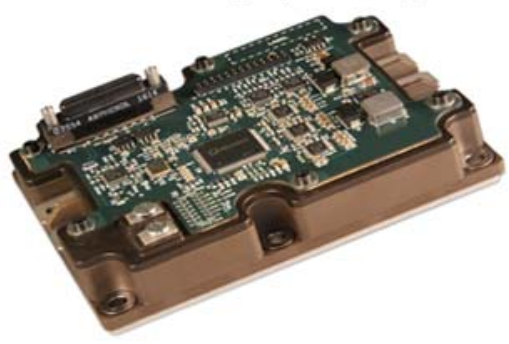

Fig. 1: Microchip custom Power Core Module (PCM) prototype

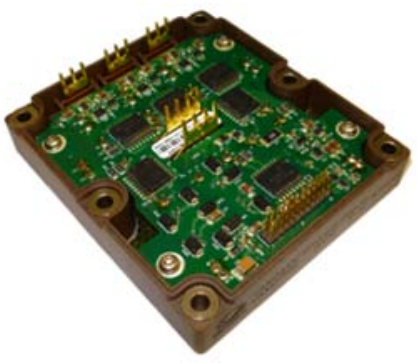

Fig. 2: Microchip custom High-Power Electronics Module (HPEM) prototype 
A summary comparison of the key features of these two designs is shown in Table I below.

Table I: Comparison of PCM and HPEM

\begin{tabular}{|c|c|c|}
\hline & PCM & HPEM \\
\hline Nominal HVDC supply & $540 \mathrm{VDC}$ & $540 \mathrm{VDC}$ \\
\hline Power rating $(540 \mathrm{~V})$ & $5 \mathrm{kVA}$ & $5 \mathrm{kVA}$ \\
\hline $\begin{array}{l}\text { Nominal peak output } \\
\text { current }\end{array}$ & $25 \mathrm{~A}$ & $25 \mathrm{~A}$ \\
\hline Motor drive architecture & Three-phase half-bridge & Three-phase half-bridge \\
\hline $\begin{array}{l}\text { Dimensions including } \\
\text { telemetry PCB } \\
\text { Assembly (PCBA) }\end{array}$ & $105 \mathrm{~mm} \times 85 \mathrm{~mm} \times 30 \mathrm{~mm}$ & Not applicable \\
\hline $\begin{array}{l}\text { Dimensions without } \\
\text { telemetry PCBA }\end{array}$ & $105 \mathrm{~mm} \times 85 \mathrm{~mm} \times 25 \mathrm{~mm}$ & $\begin{array}{l}92 \mathrm{~mm} \times 82 \mathrm{~mm} \times \\
19 \mathrm{~mm}\end{array}$ \\
\hline Connections & Screw terminals & Solderable pins \\
\hline Gate Drive & $\begin{array}{l}\text { SiC MOSFET option: Infineon } \\
1 \text { EDI60I12AF [11] with } 10 \Omega \text { gate resistor } \\
\text { on driver PCBA and } 5 \Omega \text { gate resistor on } \\
\text { substrate assembly. } \\
\text { IGBT option: Infineon } 1 \text { EDI60I12AF with } \\
10 \Omega \text { gate resistor on driver PCBA and no } \\
\text { gate resistor on substrate assembly. }\end{array}$ & $\begin{array}{l}\text { Texas Instruments } \\
\text { ISO5852 [12] with } 10 \Omega \\
\text { gate resistor on driver } \\
\text { PCBA and no additional } \\
\text { gate resistor on substrate } \\
\text { assembly. }\end{array}$ \\
\hline
\end{tabular}

\section{Test Setup}

The PCM test setup is shown in Fig. 3. The STE interface PCBA provides an interface between the PCMs and the IGLOO2 evaluation board [13]. The IGLOO2 board manages the communication between the modules under test and a PC, which logs the data. The HPEM test setup is similar to that shown in Fig. 3 with the STE interface PCBA removed and the PCM replaced by the HPEM.

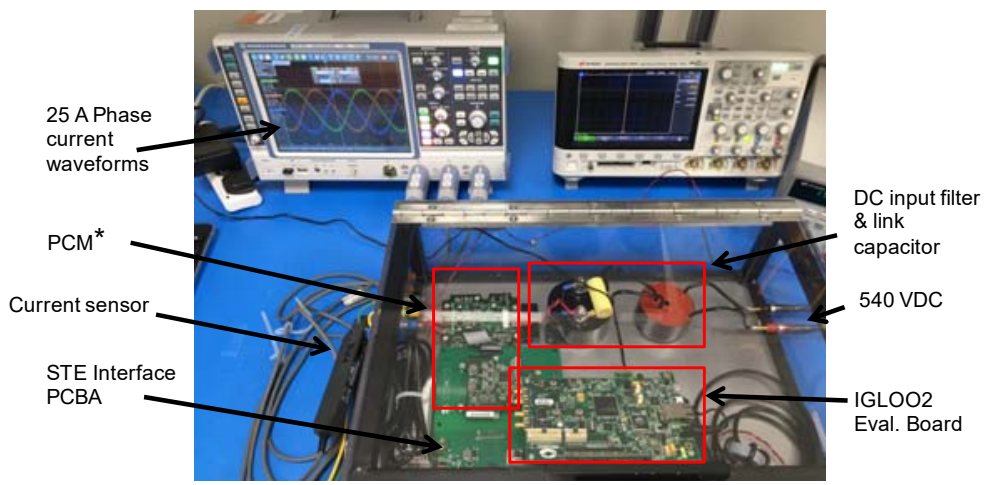

Fig. 3: PCM Test Setup

* The PCM telemetry board is removed from the assembly and placed on the STE interface PCBA. 
The high voltage supply is set at $540 \mathrm{~V}$ and the load used for the testing comprises of a $2.5 \mathrm{mH}$ inductor and $2.2 \Omega$ resistor per output phase. The output frequency is set at $400 \mathrm{~Hz}$ with a modulation index of 0.629 .

The filtered three-phase output currents from the PCM-SiC-80mR unit is displayed in Fig. 4. This illustrates the nominal peak output current of $25 \mathrm{~A}$ and is representative of the output currents from all modules in this study. However, without filtering, as can be seen in Fig. 5, the SiC configuration is noisier than that of the IGBT.

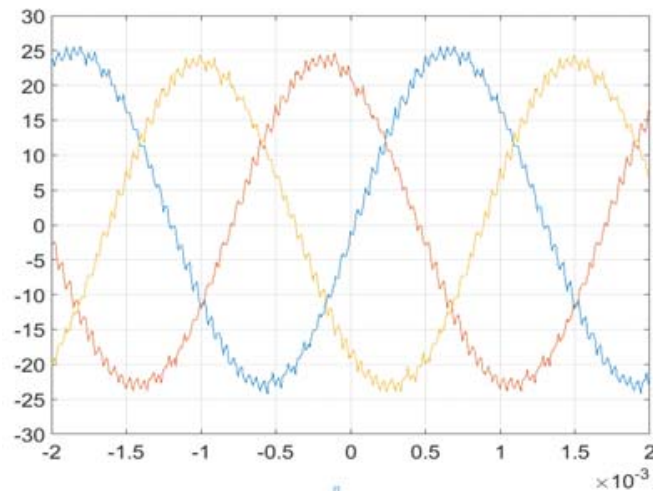

Fig. 4: PCM 3-phase output currents

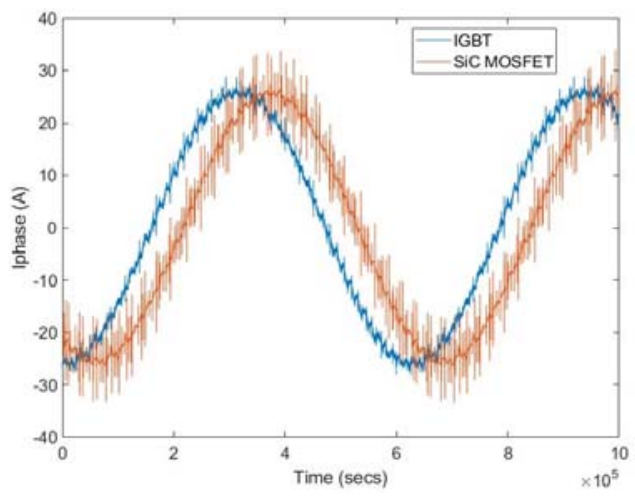

Fig. 5: PCM-SiC and PCM-IGBT Output Current

\section{Gate Drive Voltage Measurements and Simulations}

\section{Initial Gate-Source Voltage Measurements}

With a switching frequency $\left(\mathrm{F}_{\mathrm{SW}}\right)$ of $10 \mathrm{kHz}$ and a dead-time of $500 \mathrm{~ns}$, the gate-source $\left(\mathrm{V}_{\mathrm{GS}}\right)$ switching waveforms for one of the phases, designated phase ' $U$ ', was recorded over a $2.4 \mathrm{~ms}$ duration. After the dead-time delay, following the turn-off of the upper switch, the lower switch turns on. The miller effect then becomes evident, resulting in a temporary reduction of the gate-source voltage on the lower switch and a corresponding positive spike in the gate-source voltage of the upper switch [10]. The results are displayed for negative output current as this condition was shown to present the higher transients. Fig. 6 shows these waveforms for the PCM-IGBT module and comparisons of this voltage spike from the three $\mathrm{SiC}$ test units are illustrated in Fig. 7. As shown, the spikes are much larger for the $\mathrm{SiC}$ modules, with the HPEM unit having the highest amplitude. The IGBT module shows only a minor increase in voltage as the lower switch turns on. The HPEM-SiC$40 \mathrm{mR}$ module voltage increased from $-4.5 \mathrm{~V}$ to $7.72 \mathrm{~V}$, while the PCM modules containing the $40 \mathrm{~m} \Omega$ and $80 \mathrm{~m} \Omega \mathrm{SiC}$ MOSFETs increased to peaks of $3.57 \mathrm{~V}$ and $-0.59 \mathrm{~V}$ respectively. Care must be taken to ensure the transients do not switch-on the power semiconductor device as this would result in both switches being on simultaneously, resulting in a shoot-through condition with potentially catastrophic results including device and system failure. 


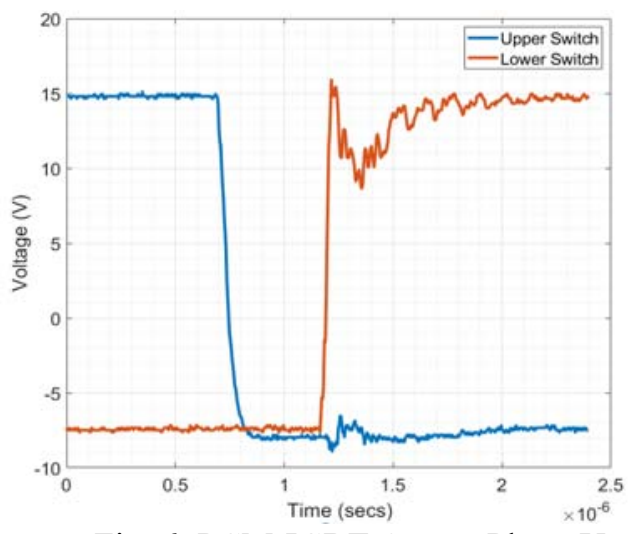

Fig. 6: PCM-IGBT Output Phase U

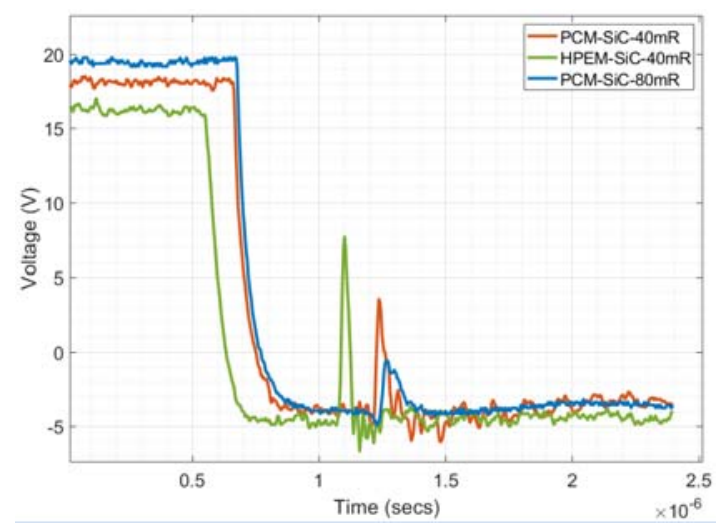

Fig. 7: Upper Switch Phase U of PCM \& HPEM $\mathrm{SiC}$ modules

\section{Gate Drive Analysis using Simulation}

Simulation results for the $80 \mathrm{~m} \Omega$ model, using a vendor-supplied PSPICE model, are shown in Fig. 8 and illustrate similar $\mathrm{V}_{\mathrm{GS}}$ behaviour to the measured results in Fig. 7. The simulation displays a voltage spike of $4.82 \mathrm{~V}$ above the $-5 \mathrm{~V}$ ideal turn-off voltage. This compares with the $4.35 \mathrm{~V}$ pk-pk measurement from the equivalent PCM-SiC-80mR unit as displayed in Fig. 7.

After verifying the simulation profile and measurements compare favourably with the measured results, the model was used to investigate methods of reducing the transient. Changing the $10 \Omega$ gate turn-off resistance on the driver board to $2 \Omega$ was evaluated. It was expected that this would result in a lower voltage at the gate for the given transient current resulting from the fast transition at the output of the phase leg. The improved results are shown in Fig. 9 with a $1.73 \mathrm{~V}$ reduction in the peak voltage.

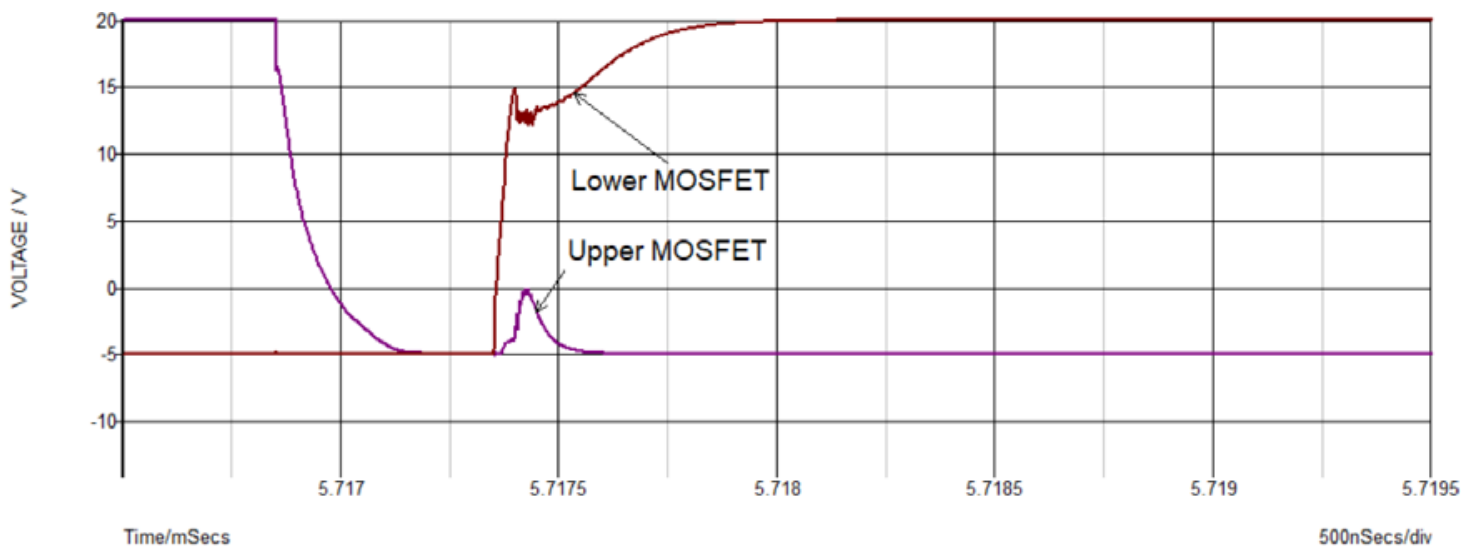

Fig. 8: Simulated $\mathrm{V}_{\mathrm{GS}}$ of PCM-SiC-80mR with $10 \Omega$ turn-off resistor on driver PCBA 


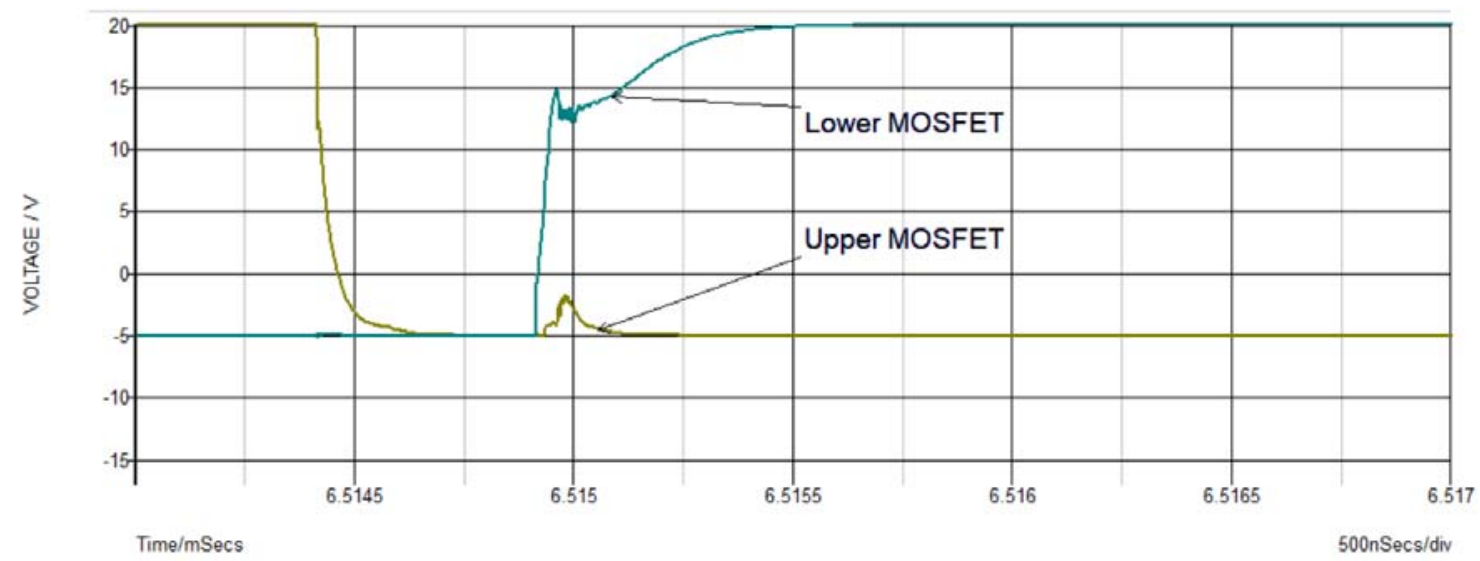

`Fig. 9: Simulated $\mathrm{V}_{\mathrm{GS}}$ of PCM-SiC-80mR with $2 \Omega$ turn-off resistor on driver PCBA

\section{Measurements on a Modified Unit}

As a result of the positive simulation data, the phase $\mathrm{U}$ turn-off $10 \Omega$ resistor was replaced on the driver PCBA with a $2 \Omega$ alternative and this modification yielded the results shown in Fig. 10 and magnified in Fig. 11. The results were favourable with a $0.8 \mathrm{~V}$ reduction in the peak voltage.

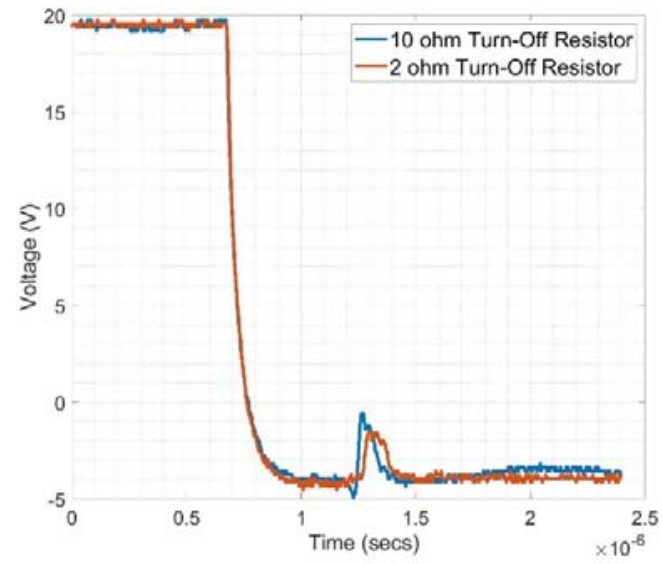

Fig. 10: Comparison of measurements with $10 \Omega$ and $2 \Omega$ turn-off resistors

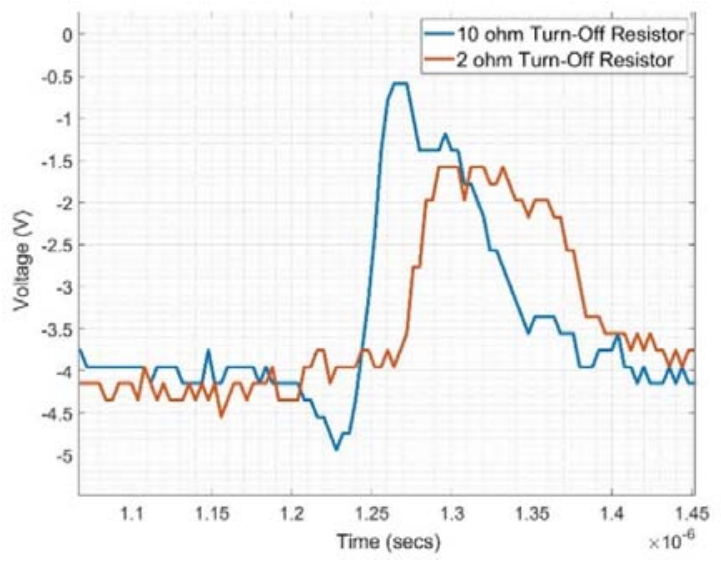

Fig. 11: Magnified view of $10 \Omega$ and $2 \Omega$ turn-off resistors effects

\section{Power Dissipation and dV/dt Analysis}

In addition to gate-drive measurements, the power dissipation and $\mathrm{dV} / \mathrm{dt}$ data was also recorded for the PCM-SiC-40mR and PCM-IGBT units for varying gate resistor configurations. Using a Voltech PM6000 power analyser, each of the inverter's three phase voltages, currents, true power and apparent power were monitored and the power losses and efficiencies calculated. Some companies working on motor drive systems currently specify a maximum $\mathrm{dV} / \mathrm{dt}$ requirement of $5-6 \mathrm{kV} / \mathrm{us}$ in their systems. This could be largely for EMI purposes but also an excessive dV/dt may cause damage to other elements of the system, for example, the electrical motor. The PCM-SiC-40mR unit, with resistors totalling $15 \Omega$ in the gate drive circuit had a measured $\mathrm{dV} / \mathrm{dt}$ in excess of this value so additional gate resistance was added. This had a positive effect on reducing the $\mathrm{dV} / \mathrm{dt}$ as shown in Table II. The gate resistance of PCM-IGBT was also modified to yield a comparable $\mathrm{dV} / \mathrm{dt}$ result to the SiC MOSFET unit. 
Table II: dV/dt and Power Loss Measurements

\begin{tabular}{|l|l|l|l|l|}
\hline Unit & $\begin{array}{l}\text { External Gate } \\
\text { Resistance }\end{array}$ & $\begin{array}{l}\text { Measured max. } \\
\mathrm{dV} / \mathrm{dt}\end{array}$ & $\begin{array}{l}\text { Measured Power } \\
\text { Dissipated }\end{array}$ & $\begin{array}{l}\text { Measured } \\
\text { Efficiency }\end{array}$ \\
\hline PCM-SiC-40mR & $15 \Omega$ & $16 \mathrm{kV} / \mathrm{us}$ & $26.6 \mathrm{~W}$ & $99.2 \%$ \\
\hline PCM-SiC-40mR & $48 \Omega$ & $6 \mathrm{kV} / \mathrm{us}$ & $39.2 \mathrm{~W}$ & $98.8 \%$ \\
\hline PCM-IGBT & $5.11 \Omega$ & $6 \mathrm{kV} / \mathrm{us}$ & $98 \mathrm{~W}$ & $97.0 \%$ \\
\hline
\end{tabular}

The following characteristics are observed:

- Increasing the gate resistance on the SiC MOSFET unit reduces the $\mathrm{dV} / \mathrm{dt}$ but increases the power dissipation and reduces efficiency.

- The gate resistance for the IGBT, to receive a comparable max. $\mathrm{dV} / \mathrm{dt}$ as the SiC MOSFET, is much lower, as the IGBT is a slower switching device resulting in lower $\mathrm{dV} / \mathrm{dt}$ values.

- The difference in power dissipation and efficiency between the two semiconductor technologies, for a similar $\mathrm{dV} / \mathrm{dt}$ is evident. This also illustrates the higher efficiency of the $\mathrm{SiC}$ MOSFET solution, even if the $\mathrm{dV} / \mathrm{dt}$ is reduced to a value comparable with an IGBT alternative.

Having increased the gate drive resistance of the unit significantly, the $\mathrm{V}_{\mathrm{GS}}$ of the MOSFETs was remeasured. As shown in Fig. 12, the switch-off time of the upper MOSFET has increased significantly, compared with the data recorded for the same 2.4us duration in Fig. 7. The switch-on time of the lower MOSFET is also much reduced from similar measurements recorded in [10] and that of the IGBT shown in Fig. 6. Even though it was shown in Fig. 9 and Fig. 10 that a reduction in gate resistance had positive effects, increasing this resistance and thereby causing a significant reduction in switching speeds and $\mathrm{dV} / \mathrm{dt}$ values, also results in lower transients.
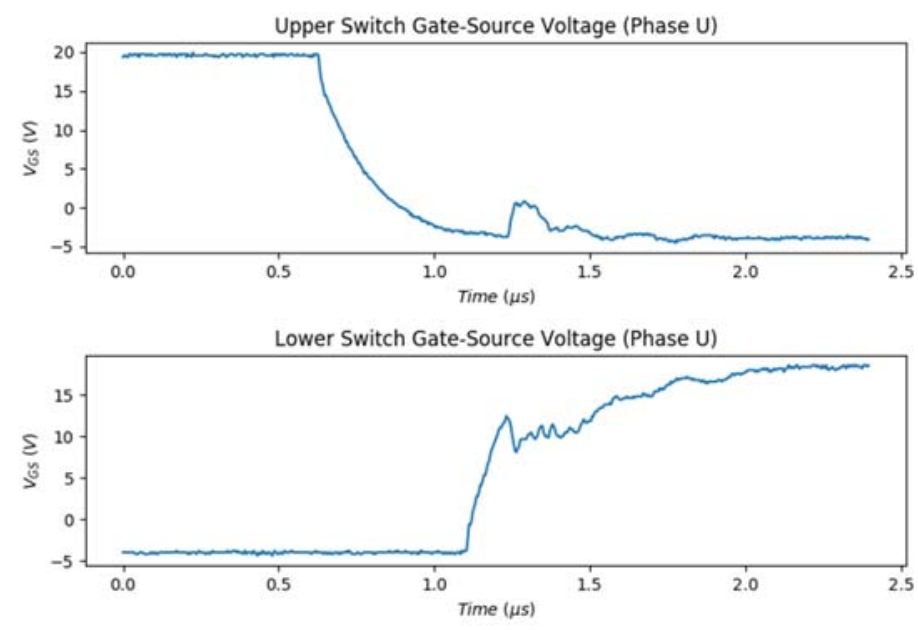

Fig. 12: $\mathrm{V}_{\mathrm{GS}}$ of Upper and Lower MOSFETs with $48 \Omega$ gate resistance

\section{Simulations and Verified Results}

The $\mathrm{dV} / \mathrm{dt}$ for the PCM-SiC-80mR solution was simulated as shown in Fig. 13 with the original external resistance of $15 \Omega$. The resulting value of $16.2 \mathrm{kV} / \mathrm{us}$ is very similar to the measured value shown in Table II. Adding additional gate resistance, on both upper and lower MOSFETs, to a value of $48 \Omega$, yielded a dV/dt value of $5.6 \mathrm{kV} / \mathrm{us}$, as shown in Fig. 14, which is slightly lower than the measurement. However, comparing the figures, which have the same $200 \mathrm{~ns} /$ division on the $\mathrm{x}$-axis, 
illustrates the significant reduction in rise and fall times of the power semiconductor switch-on and switch-off times due to the increase in gate resistance. Furthermore, due to the slower switching

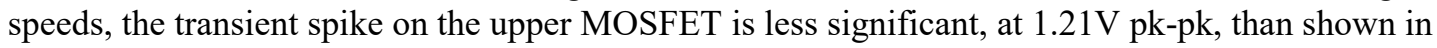
Fig. 8 and Fig. 9. Similar to the measured results, the simulations illustrate the correlation between gate resistance, transients on the gate drive, switching speed of the FETs and dV/dt.

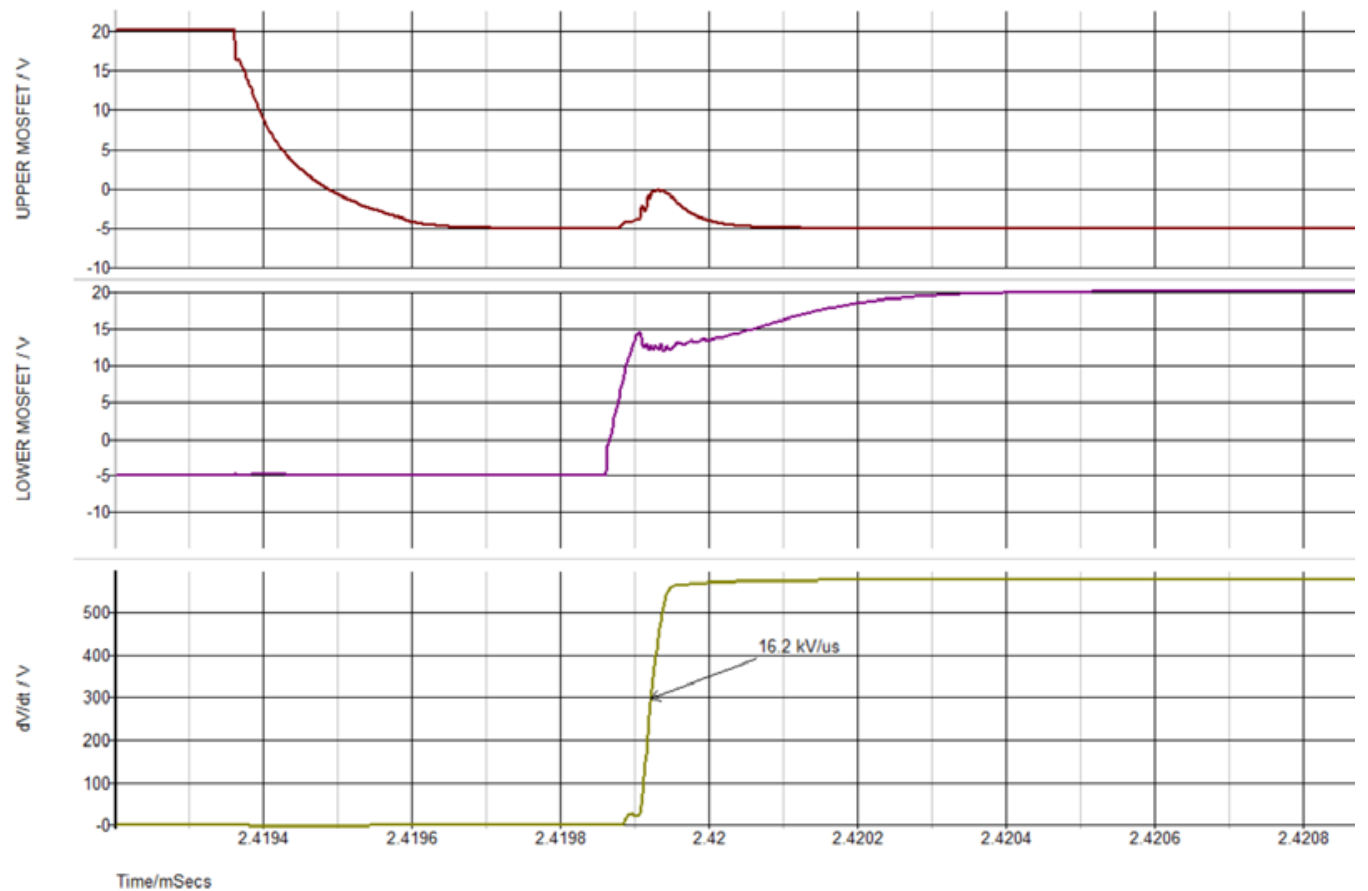

Fig. 13: dV/dt Results from Simulation with $15 \Omega$ gate resistance

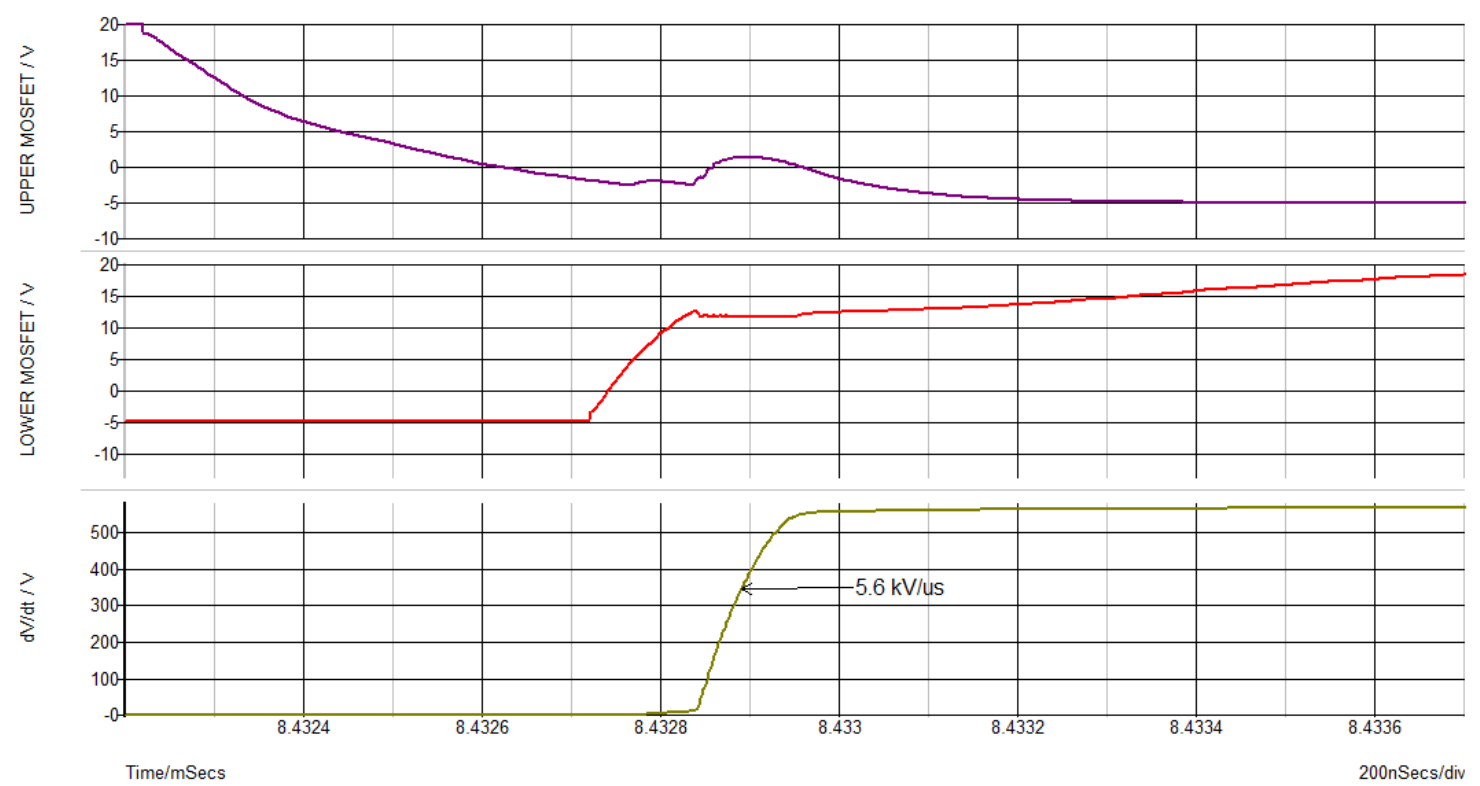

Fig. 14: dV/dt Results from Simulation with $48 \Omega$ gate resistance

When comparing the simulated power dissipations of the MOSFETs for $15 \Omega$ and $48 \Omega$ gate resistance options, it can be seen that the value increases with larger gate resistance, which also corresponds with the measured results displayed in Table II. The simulated results are shown in Table III. 


\section{Table III: Simulated Power Dissipations}

\begin{tabular}{|l|l|}
\hline $\begin{array}{l}\text { External Gate } \\
\text { Resistance }\end{array}$ & $\begin{array}{l}\text { Measured Power } \\
\text { Dissipated }\end{array}$ \\
\hline $15 \Omega$ & $30 \mathrm{~W}$ \\
\hline $48 \Omega$ & $34.5 \mathrm{~W}$ \\
\hline
\end{tabular}

\section{Conclusion}

This paper analyses the gate drive signals of four power inverter modules, comparing measurements from various SiC MOSFET and IGBT configurations. Though there are similarities in the waveform profile, the results display the effects of gate resistances and differences in the two module designs. All four show a voltage transient on the gate drive signal during switching and the results are presented for the condition when the lower switch of a phase-leg turns on and the output current is negative. These transients are higher in SiC MOSFETs than Si IGBTs and if the transients are sufficiently high, it may result in the upper and lower switches being momentarily on simultaneously. This may lead to reduced performance, degraded operation over time or device failure. It is therefore desirable to reduce the amplitudes of such transients and this paper presents how this can be done by reducing the gate resistance when the power semiconductor switching speeds are sufficiently high to adversely impact the gate-drive.

In addition, the correlation between the gate drive signal and the $d V / d t$ of the MOSFET $V_{D S}$ is shown where an increase in gate resistance results in a decrease of $\mathrm{dV} / \mathrm{dt}$. Although the gate resistance of the $\mathrm{SiC}$ MOSFETs used in this study was larger than that of the IGBTs, the $\mathrm{dV} / \mathrm{dt}$ of the former was still higher. This displays the increased switching speed characteristics of the SiC devices over the IGBTs and may be particularly applicable in designs where existing IGBT solutions are being replaced by $\mathrm{SiC}$ MOSFET alternatives. The $\mathrm{dV} / \mathrm{dt}$ of the semiconductor switches is particularly important when the modules are connected to the next level assemblies, where EMI filtering and connections to other system elements, for example electrical motors, must be considered. The $\mathrm{dV} / \mathrm{dt}$ of a SiC MOSFET module used in this study was measured at a maximum of $16 \mathrm{kV} / \mathrm{us}$, which is excessive for some motor drive applications. With increased gate resistance, the $\mathrm{dV} / \mathrm{dt}$ can be reduced and it was shown that an increase from $15 \Omega$ to $48 \Omega$ reduced the measured $\mathrm{dV} / \mathrm{dt}$ by $62.5 \%$. The switching speeds and $\mathrm{dV} / \mathrm{dt}$ have a directly proportional effect on the gate-drive transients so as these are decreased, a corresponding positive effect is seen at the semiconductor gate. However, as illustrated by simulated and measured results, these benefits result in increased power dissipation so this disadvantage must also be considered.

From the analysis and measurements presented in this paper, it can be deduced that the gate drive resistance of SiC MOSFETs have direct influences on gate-drive, $\mathrm{dV} / \mathrm{dt}$ and power dissipation of the devices and depending on the system requirements of the application, a trade-off analysis may be required to determine the appropriate configuration and ensure appropriate results. 


\section{References}

[1] P. W. Wheeler, “The more electric aircraft: Why aerospace needs power electronics?" Power Electronics and Applications, 2009. EPE '09. 13th European Conference on, pp. 1-30, Sept. 2009.

[2] S. O’Donnell, A. Castellazzi, J.L. Debauche, P. Wheeler, "Silicon Carbide MOSFETs in More Electric Aircraft Power Converters: The Performance and Reliability benefits over Silicon IGBTs for a specified Flight Mission Profile", 2016 18th European Conference on Power Electronics and Applications, EPE'16 ECCE Europe, pp 1-10, Sept. 2016.

[3] D. De, A. Castellazzi, S. Lopez-Arevalo, A. Lamantia, "SiC MOSFET based avionic power supply", $7^{\text {th }}$ IET International Conference on Power Electronics, Machines and Drives (PEMD 2014), pp. 1-6, Apr. 2014.

[4] A. Elasser and T.P. Chow, "Silicon Carbide Benefits and Advantages for Power Electronics Circuits and Systems”, Proc. IEEE, Vol. 90, pp. 969-986, 2002.

[5] J. Millan, P. Godignon, X. Perpinya, A. Perez-Tomas, and J. Rebollo, “A Survey of Wide Band Gap Power Semiconductor Devices," IEEE Transactions on Power Electronics., Vol. 29, No. 5, pp. 2155-2163, May 2014.

[6] A. Hussein, A. Castellazzi, P. Wheeler, C. Klumpner, "Performance Benchmark of Si IGBTs vs. SiC MOSFETs in small-scale wind energy conversion systems", 2016 IEEE International Power Electronics and Motion Control Conference (PEMC), pp 963-968, Sept. 2016.

[7] J. Biela, M. Schweizer, S. Waffler, B. Wrzecionko, J. W. Kolar, "SiC vs. Si-Evaluation of potentials for performance improvement of Inverter and DC-DC Converter Systems by SiC Power Semiconductors", IEEE Transactions on Industrial Electronics, Vol. 58, No. 7, July 2011.

[8] A. Ong, J. Carr, J. Balda, A. Mantooth, “A Comparison of Silicon and Silicon Carbide MOSFET Switching Characteristics”, IEEE Region 5 Technical Conference, pp. 273-377, April 2007.

[9] E. Gurpinar, S. Lopez-Arevalo, J. Li, D. De, A. Castellazzi, L. Mills, “Testing of a lightweight SiC power module for avionic applications", $7^{\text {th }}$ IET International Conference on Power Electronics, Machines and Drives (PEMD 2014), pp 1-6, April 2014.

[10] S. O’Donnell, A. Castellazzi, L. Egan, V. Walsh, P. Wheeler, "Device-Package Interaction and Gate Driver Layout Analysis in SiC MOSFET Power Modules for More Electric Aircraft Motor Drive Applications", 2018

20th European Conference on Power Electronics and Applications, EPE'18 ECCE Europe, pp. 1-10, Sept. 2018.

[11] Infineon, 1EDI EiceDRIVER ${ }^{\mathrm{TM}}$ Compact Datasheet, Rev. 2.0, 2014.

[12] Texas Instruments, ISO5852S High-CMTI 2.5-A and 5-A Reinforced Isolated IGBT, MOSFET Gate Driver Datasheet, August 2015, Revised January 2017.

[13] Microsemi, UG0478 User Guide IGLOO2 FPGA Evaluation Kit, Revision 4.1, 2017. 